\title{
ONCE BITTEN, TWICE SHY: UPGRADING TRADITIONAL MARKETS AS A STRATEGY TO PROMOTE COMPLIANCE WITH SAFETY PROTO- COLS OF, AND BEAT, COVID-19 HANDS-DOWN
}

\author{
Oyebanji Anthony Olajuyin ${ }^{1} \otimes\left(\mathbb{B}\right.$, Kehinde Sunday Oluwadiya ${ }^{2}$, Ademola Busayo \\ Olajuyin $^{3}{ }^{(0)}$, Adebola Ayotomiwa Olajuyin ${ }^{4}$, Femi Ojo Ogunboyo ${ }^{5}$ (D), Oladele Simeon \\ Olatunya $^{6}{ }^{(0)}$, Atilade Waheed Adegbiji ${ }^{1}$ and Toye Gabriel Olajide ${ }^{7}$ \\ ${ }^{1}$ Department of Ear, Nose and Throat, Ekiti State University Teaching Hospital, Ado Ekiti, Ekiti State, Nigeria \\ ${ }^{2}$ Department of Surgery, Ekiti State University Teaching Hospital, Ado-Ekiti, Ekiti State, Nigeria \\ ${ }^{3}$ Department of Family Medicine, Ekiti State University Teaching Hospital, Ado-Ekiti, Ekiti State, Nigeria \\ ${ }^{4}$ Department of Obs-gynaecology, Ekiti State University Teaching Hospital, Ado-Ekiti, Ekiti State, Nigeria \\ ${ }^{5}$ Department of Statistics, Faculty of Science, Ekiti State University, Ado-Ekiti, Ekiti State, Nigeria \\ ${ }^{6}$ Department of Paediatrics, Ekiti State University Teaching Hospital, Ado-Ekiti, Ekiti State, Nigeria \\ ${ }^{7}$ Department of Ear, Nose and Throat, Federal Teaching Hospital, Ido-Ekiti/Afe Babalola University, Ado-Ekiti, Ekiti State, \\ Nigeria
}

Received 6 June 2021

Accepted 18 June 2021

Published 30 June 2021

Corresponding Author

Oyebanji Anthony Olajuyin, oyeba

njiolajuyin@yahoo.com

DOI 10.29121/

granthaalayah.v9.i6.2021.4056

Funding: This research received no specific grant from any funding agency in the public, commercial, or not-for-profit sectors.

Copyright: (C) 2021 The Author(s). This is an open access article distributed under the terms of the Creative Commons Attribution License, which permits unrestricted use, distribution, and reproduction in any medium, provided the original author and source are credited.

\section{ABSTRACT}

The traditional market has characteristic features that could make effective compliance with Covid-19 safety protocols in the market a difficult task to accomplish, thus, predisposing the market and the entire community to the resurgence of Covid-19 pandemic. This paper described the factors in the traditional markets that could make effective compliance with Covid-19 safety protocols a mission impossible. The paper emphasizes the need to upgrade the traditional market as a strategy to eliminate those innate factors that militate against effective compliance with Covid-19 safety protocols. The study was a prospective, comparative analysis of compliance with Covid-19 safety protocols in the Traditional Markets (TM) and Modern Markets (MM) in Ekiti State, Southwest Nigeria. The results showed that the traditional markets were majorly the open-air types with propensity for overcrowding, clustering, rowdiness and long business hours. The compliance scores across all the Covid-19 safety protocols and especially physical distancing were very poor in the traditional markets compared with the modern markets. This re-affirms the existence of anti-compliance factors of Covid-19 safety protocols in the traditional markets. There is therefore the need to upgrade the traditional markets with a view to facilitate compliance with the Covid-19 safety protocols and subdue the resurgence of Covid-19 pandemic in Ekiti State, Southwest Nigeria.

Keywords: Traditional Market, Covid19, Safety Protocols, Compliance, Upgrade 


\section{INTRODUCTION}

Of recent, no other disease has shocked the global community to the marrow as the novel Covid-19 pandemic. The Covid-19, through its ravaging effects has registered its presence in every nook and cranny of the world. As of 26 September 2020, about 32 million cases including 989,728 deaths have been reported worldwide Center (2020). It was first reported in Wuhan city, China, in 2019 and was declared a pandemic by the Organization (2020b) on 11 March 2020. Reports from China showed that some of the earliest known cases of Covid-19 were traced to the traditional food market. According to the Organization (2020a), some of the earliest known cases of Covid-19 had a link to a wholesale food market in Wuhan city, China and many of the initial patients were stall owners, market employees, or regular visitors to this market. Also, in Lima (Peru), an estimated $79 \%$ of vendors in the open-air retail food markets have fallen ill with Covid-19 Food and Nations (2021). Although, in our own setting, there was no comparative study of the Traditional Market (TM) and Modern Markets (MM) for Covid-19 incidence, observation has shown that compliance with the Covid-19 safety protocols especially physical distancing in the TM is inconsistent compared with MM. Furthermore, to enforce compliance in the traditional market by the law-enforcement agents is something of a herculean task. Therefore, it is possible that these, coupled with other factors might have raised the bar of Covid-19 infection in the TM above that in the MM.

Culturally, the traditional markets (TM) are the most widely patronized for goods and services. For instance, there are handy laborers who could easily 'upload' and 'download' goods for buyers and sellers in the markets. Also, the TM provides readymade markets for cheap and staple food. The duration of business transaction during which people are into contact runs into hours, sometimes from dawn till dusk. Hence, the TM is often swarmed with many buyers and sellers thereby causing heavy human traffic. Given these characteristics, it is likely that the TM may be challenged by the inability of people to comply with Covid-19 safety protocols. As noted in the literature, compliance has remained a concern, especially in Nigeria Agusi et al. (2020). Also noted by scholars is that; compliance with directives and instructed regimen is a longstanding and known problem in medicine Irwin and Mansdorf (2020). Except therefore, there is strict enforcement, compliance with Covid-19 safety protocols in the TM may be nothing more than a mirage. However, before any enforcement can be imposed on the TM, there is the need for a baseline data to guide stakeholders on why, where, when and how the compliance should be enforced. According to Irwin and Mansdorf (2020), providing reliable, accurate and dependable information is a major element in ensuring compliance with Covid-19 guidelines. Furthermore, the enforcement would only be effective if the TM is conducive for people to exercise their franchise regarding compliance with the Covid-19 safety protocols. In this regard, the TM may need to be restructured such that people can adopt the recommended physical distancing, wash their hands with soap and running water, use hand sanitizer and queue up for the use of infrared thermometer. It is on this basis that this 
study was conducted. The study attempts to sensitize the stakeholders on the need to upgrade traditional markets to modern markets with a view to facilitate compliance with the Covid-19 safety protocols and prevent resurgence of the pandemic in Ekiti State, Southwest, Nigeria.

\section{METHODOLOGY}

\section{Study Setting}

This was an observational report of compliance with Covid-19 safety protocols at the traditional markets in Ekiti State, Southwest, Nigeria. The study was conducted between June 2020 and September 2020 at the three geopolitical (senatorial) districts of Ekiti State, South-West, Nigeria. The study population was selected by systematic random sampling technique.

Study design and data Collection

Online and offline surveys of the compliance with the Covid-19 safety protocols were conducted among people in selected domains using validated questionnaires. The questionnaires were on a 5-point Likert's scale with a score of 1 being very poor and a score of 5 being very good. The online survey, an opinion poll, was conducted by requesting respondents to fill online forms based on their view about residents' compliance with Covid-19 safety protocols at specified domains while the offline survey was conducted by asking field workers to complete questionnaires on passers-by at designated centers. For every 20 persons, the number of persons that; wore facemasks, washed hand with soap and water, used hand sanitizer, had their temperature checked with infrared thermometer and maintained the recommended physical distance were noted and recorded using Likert's scale as follows:

1. $0-4$ persons $=$ Very Poor

2. $5-8$ persons $=$ Poor

3. $9-12$ persons $=$ Fair

4. $13-16=$ Good

5. $17-20=$ Very Good.

Data analysis

This was done using Statistical Program for Social Sciences (SPSS IBM) software version 20 using simple descriptive statistics. 


\section{RESULTS}

Table 1 Comparative scores for the compliance with the Covid-19 safety protocols in the Traditional Markets (TM) and Modern Markets (MM)

\begin{tabular}{lcccccc}
\hline $\begin{array}{c}\text { Public } \\
\text { domains }\end{array}$ & $\begin{array}{c}\text { Physical } \\
\text { distanc- } \\
\text { ing }\end{array}$ & Face mask & $\begin{array}{c}\text { Hand } \\
\text { washing }\end{array}$ & $\begin{array}{c}\text { Use of } \\
\text { sanitizer }\end{array}$ & $\begin{array}{c}\text { Use of } \\
\text { infrared } \\
\text { Ther- } \\
\text { mometer }\end{array}$ & $\begin{array}{c}\text { Overall } \\
\text { compliance }\end{array}$ \\
$\begin{array}{l}\text { Traditional } \\
\text { Markets }\end{array}$ & 1.60 & 2.98 & 1.02 & 1.0 & 1.53 & 1.63 \\
$\begin{array}{l}\text { Modern } \\
\text { Markets }\end{array}$ & 4.31 & 4.0 & 3.40 & 3.40 & 2.61 & 3.50 \\
\hline
\end{tabular}

[Scores: very poor $=1$, Poor $=2$, fair $=3$, Good $=4$, Very good $=5$ ]

In all, 448 (270 online and 178 offline) questionnaires were completed. The result shows that the traditional markets consist of $48.93 \%$ open air, $34.24 \%$ open stalls and $16.83 \%$ locked-up shops. The transactions were characteristically overcrowded, clustered and lengthy in business hours. The comparative scores for the compliance with the Covid-19 safety protocols in the Traditional Markets (TM) and Modern Markets (MM) is shown in Table 1 . The relative compliance with the individual Covid-19 safety protocols in the Traditional Markets (TM) is shown in Figure 1 while the types and percentage distribution of the traditional markets in the study locale are shown in Figure 2. The enforcement of compliance with the safety protocols was inconsistent in the TM compared with the MM. There was a good correlation between the online and offline surveys with Spearman correlation coefficient ( $r$ ) of $0.98(\mathrm{p}<0.001)$.

\section{DISCUSSION}

This study observed that $83.17 \%$ of the traditional markets (TM) in the study locale were either open-air or open stalls. With this structural feature, the TM is vulnerable to unrestricted influx of people especially on the market days thus creating congestion and rowdiness. Consequently, maintaining the recommended physical distancing in this situation may be a hard nut to crack. This is supported by finding a poor compliance with the physical distancing in the present study. Previous report has shown that compliance with physical distancing is a major challenge in Nigeria Agusi et al. (2020). As the present study showed, compliance with physical distancing in the traditional market on the Likert's scale was 1.60 as against 3.31 in the modern market. This difference was statistically significant $(\mathrm{p}<0.001)$, using independent sample t-test. Therefore, there is the need to upgrade the traditional market to a state that will allow physical distancing to be maintained during business transactions in the markets. 


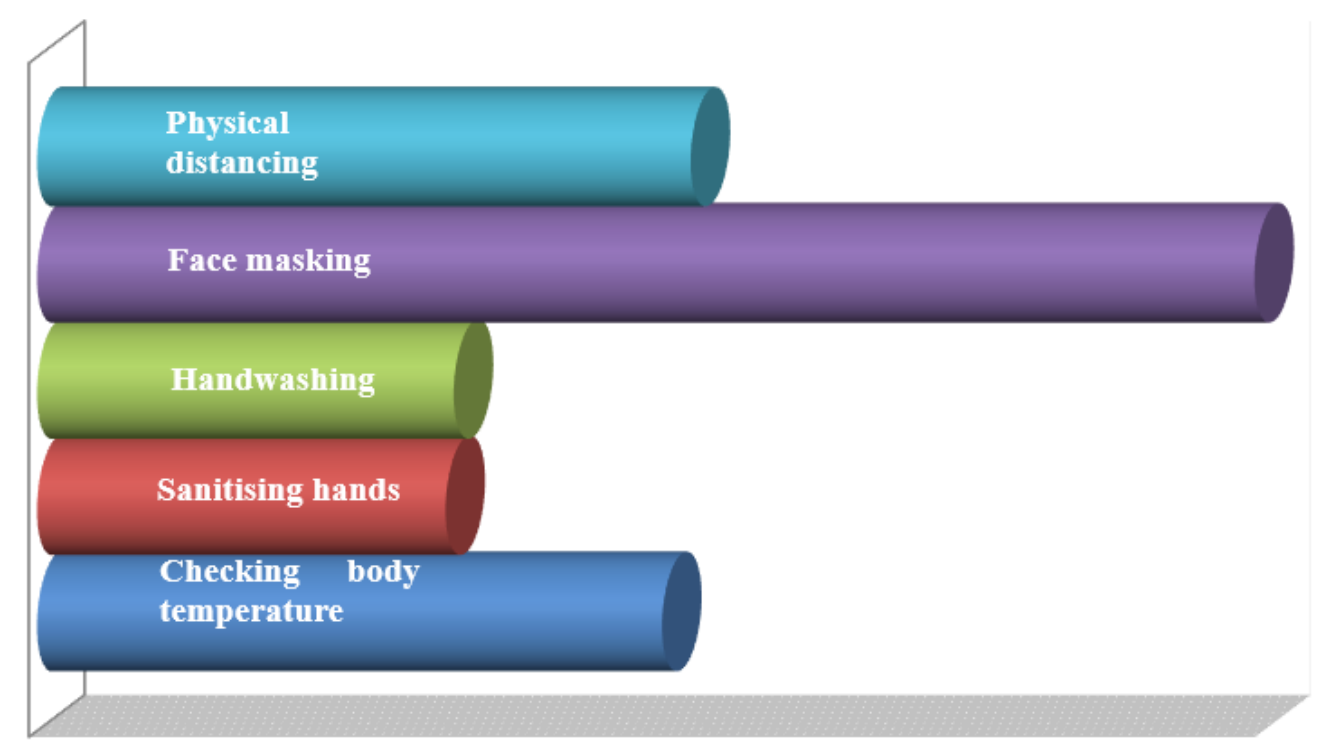

Figure 1 Relative compliance with the individual Covid-19 safety protocols in the Traditional Markets (TM)

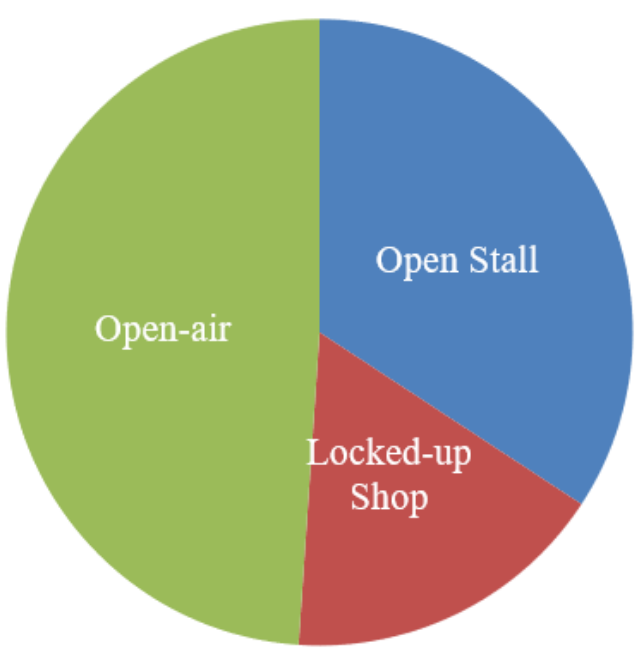

Figure 2 Types and Percentage distribution of the traditional markets in the study locale. 
Masking the nose and mouth at the traditional market was also observed to be poor in this study. As the study showed, the compliance score on the Likert's scale was 2.98 as against the mean score of 4.0 for modern markets. This tendency for people in the TM to ignore compliance even at their own peril has been reported by scholars. Irwin had noted that people routinely do not do what is good for them and refuse to cease behavior that is bad for them. However, the reason for the poor compliance in the present study may be; the discomfort experienced by some people with the use of facemask. This is particularly so with the TM where there is overcrowding, clustering and congestion as against the MM where there is enough ventilation. Furthermore, unlike the MM where the entrances are guarded by personnel that enforce compliance with the use of facemask, the entrances to TM are unmanned thereby allowing passage of every Dick and Harry into the market without facemask. Now, it is important to note that clustering and mask off are potent factors that facilitate the spread of Covid-19 while social distancing and mask on have been found to insulate against Covid-19 virus. In their paper, Cheng and Al (2020) reported that 11 Covid19 clusters were observed in recreational 'mask-off' settings compared to only 3 in workplace 'mask-on' settings. Further to this, the authors noted that the distribution of facemasks to the public by the South Korea government was associated with a flattening of the pandemic curve. In a related study, Smith et al. (2020) remarked that; globally, facemasks have the potential to reduce the spread of this life-threatening illness and throwing their weight behind the proponents of mask on, Piryani et al. (2020) argued: "Absence of evidence is not evidence of absence" while the center for disease prevention and control Factsheet (2020) says: "Wear a mask that covers your nose and mouth in public setting". While these reports and recommendations subsist, nothing could be more rewarding than to create enabling environment that could facilitate enforcement and use of facemasks as these facts suggested.

Compliance with hand washing and sanitization was nearly zero at the openair/open-stall TM. The few Veronica Buckets seen were found in front of the lockedup shops. Again, this was a far cry from what was seen at the MM where compliance was found to be relatively good. The relatively higher compliance in the MM may be due to the structural and landscaping features which allow orderly placement and use of hand washing and sanitization materials at strategic places in the MM. Apart from this, the presence of security guards at the entrance to some of the MM may have facilitated the enforcement and compliance with the hand washing and sanitization procedures. These favorable features are lacking in most of the TM. This may be responsible for the poor compliance with the hygiene etiquettes and the use of infrared thermometer noted in the TM in this study. Also, the financial incapacitation of most traditional marketers could impair their ability to buy soap and hand sanitizer for hygiene etiquettes. As known, hand washing and sanitization requires recurrent funding that can only be sustained with good financial strength. Also, the cost of infrared thermometer may be too exorbitant for the traditional marketers, many of who are petty traders. As a short term measure therefore, traders may be 
enlightened on how to display their wares in orderly fashion while those selling nonessential goods should vacate the markets to reduce congestion. The markets may be fragmented so as to facilitate compliance with the recommended physical distancing. To this end, the area council can construct makeshift markets in the neighborhood for easy access to buyers. Furthermore, sellers may be encouraged to convert the spaces outside their homes into makeshift markets. In this regard, traders may be offered grants and financial inducement so as to comply with the directives. Fumigation of the central markets could be a cost effective means of ridding the markets of the pandemic. As a long-term measure, the TM may have to be restructured into locked-up shops so as to facilitate control of human traffics and enforcement of the safety protocols now and in future pandemics.

\section{CONCLUSION}

This study shows that traditional markets are majorly the open-air types with propensity for overcrowding and clustering, making compliance with the Covid-19 safety protocols especially physical distancing unattainable. The need to upgrade the markets to modern markets with a view to facilitate compliance with the Covid-19 safety protocols and prevent resurgence of pandemic in Ekiti State, Southwest Nigeria, is hereby stressed.

\section{REFERENCES}

Agusi, E. R., Ijoma, S. I., Nnochin, C. S., Njoku-Achu, N. O., Nwosuh, C. I., \& Meseko, C. A. (2020). The COVID-19 pandemic and social distancing in Nigeria: ignorance or defiance. Pan African Medical Journal, 35(Supp 2), 52-52. Retrieved from https://dx.doi .org/10.11604/pamj.supp.2020.35.2.23649 10.11604/pamj.supp.2020.35.2.23649

Center, E. (2020). Disease Prevention And Control. COVID-19 Situation Update Worldwide, As Of. Retrieved from Https://Www.Ecdc.Europa.Eu/En/Geographical

Cheng, V.-C. E., \& Al. (2020). The Role Of Community-Wide Wearing Of Face Mask For Control Of Coronavirus Disease 2019 (COVID-19) Epidemic Due To SARS-Cov-2. Journal Of Infection, 81, 107-114.

Factsheet. (2020). Center For Disease Prevention And Control. What You Should Know About COVID-19 To Protect Yourself And Others. Available At: Www.Cdc.Gov>2019-Ncov-. Accessed.

Food, \& Nations, A. O. O. T. U. (2021). Measures For Supporting Wholesale Food Markets During COVID-19. Retrieved from Http://Www.Fao.Org/3/Ca9552en/CA9552EN .PdfAccessedOn15th

Irwin, J., \& Mansdorf. (2020). Enforcing Compliance With COVID-19 Pandemic Restrictions: Psychological Aspects Of A National Security Threat. Jerusalem Center For Public Affairs. Available At.

Organization, W. H. (2020a). Coronavirus Disease (COVID-19) Situation.

Organization, W. H. (2020b). Rolling Updates On Coronavirus Disease (COVID-19). Retrieved from Https://Www.Who.Int/Emergencies/Diseases/Novel-Coronavirus-2019/ Events-As-They-HappenAccessed06 
Piryani, R. M., Piryani, S., \& Shah, J. N. (2020). Use of mask in COVID-19 era: absence of evidence is not evidence of absence. Journal of Patan Academy of Health Sciences, 7(1), 89-90. Retrieved from https://dx.doi.org/10.3126/jpahs.v7i1.28880 10.3126/jpahs .v7i1.28880

Smith, G. D., Ng, F., \& Watson, R. (2020). "Masking the evidence”: Perspectives of the COVID-19 pandemic. Journal of Clinical Nursing, 00. Retrieved from https://dx.doi.org/10.1111/ jocn.15401 10.1111/jocn.15401 